\title{
Attachment-Based Family Therapy as an Adjunct to Family-Based Treatment for Adolescent Anorexia Nervosa
}

\author{
Ingrid Wagner', Guy S. Diamond ${ }^{2}$, Suzanne Levy², Jody Russon², and \\ Richard Litster ${ }^{3}$ \\ I Queensland University of Technology, Brisbane \\ 2 Drexel University, Philadelphia \\ 3 Lady Cilento Children's Hospital, Brisbane
}

\begin{abstract}
Adolescent anorexia nervosa (AN) has a significant and long-standing impact for the health and well being of young people and their families. The determinants of illness are multi-factorial, however, adolescent AN has been consistently associated with parental distress (e.g., depression, anxiety, alcoholism), family conflict, and low parental warmth toward the adolescent. Whilst Family Based Therapy (FBT) for adolescent AN is the recommended first line of treatment, a substantial proportion of patients do not experience remission by the end of therapy or may relapse following remission. Although a range of adjuncts to FBT have been proposed, no preferred model has emerged. In this paper, we compare and contrast Attachment-Based Family Therapy (ABFT) with FBT, and argue that ABFT's focus on relationships, rather than behaviours, could make a substantive contribution to the practice of FBT. We present a case study to demonstrate how ABFT may help to alleviate some of the maintaining factors of adolescent $\mathrm{AN}$ through the repair of parent-child relational ruptures.
\end{abstract}

Keywords: anorexia nervosa, Attachment-Based Family Therapy, family-based therapy, Maudsley model, adolescents, suicide, treatment augmentation

\footnotetext{
Key Points

I Family Based Therapy (FBT) is the treatment of choice for adolescent anorexia nervosa, yet failure to remit and relapse post-remission remain challenging to the field.

2 Attachment-Based Family Therapy (ABFT) may serve as a good augmentation to FBT.

3 ABFT aims to repair factors that impact relational security (i.e., parental criticism, low parental warmth, familial conflict, and adolescent affect intolerance), which are the same factors that affect the outcomes of FBT.

4 ABFT can be introduced to augment FBT after physical stability has been achieved.

5 More research is needed to explore how ABFT might augment FBT.
}

Anorexia nervosa (AN) is a complex disorder, which presents significant challenges to those affected, their families, and the treatment teams. The etiology of the disorder is not well understood but evidence suggests that the determinants are multifactorial, consisting of social, psychological, neurological, and biological risk factors (Holliday et al., 2005; O’Brien \& Vincent, 2003; Polivy \& Herman, 2002; Strober et al., 2000). The National Comorbidity Survey (Swanson et al., 2011) estimated the

Address for correspondence: Ingrid Wagner, private practitioner and adjunct Associate Professor, School of Public Health and Social Work, Queensland University of Technology, Kelvin Grove Campus, P.O. Box 550, Toowong 4066, Brisbane, Queensland, Australia.

i.wagner@treat4life.com.au 
Ingrid Wagner et al.

median age at onset of AN to be 12.3 years, with a lifetime prevalence for adolescents aged 13 to 18 years at $0.3 \%$. Serious medical complications, high mortality rates, increased risk of suicide, and co-morbid mental disorders complicate treatment and recovery rates for youth with AN (Katzman, 2005; Swanson et al., 2011). The impact of this disorder on adolescents and their families, and the presence of untoward outcomes, are compelling reasons to promote the search for effective treatments.

This paper provides an overview of current practice in family-based treatment (FBT) for adolescent AN (Lock \& Le Grange, 2013), and argues that AttachmentBased Family Therapy ([ABFT]; Diamond, Diamond \& Levy, 2014) may be a useful adjunct to this treatment.

\section{Family-Based Treatment for Adolescent Anorexia Nervosa}

Family-based therapies that focus on eating disorder (ED) symptoms are the preferred treatment modality for adolescent AN (National Collaborating Centre for Mental Health, 2004). The FBT approach, developed at the Maudsley Hospital and subsequently manualised by Lock and Le Grange (2013), is currently the treatment of choice (Loeb \& Le Grange, 2009). It is an integrated model which draws from structural, strategic, narrative, and Milan systemic therapy models (Eisler, Lock, \& Le Grange, 2010). FBT is characterised by five treatment principles: (1) the agnostic stance toward the cause of the disorder; (2) the non-authoritarian therapeutic approach; (3) the empowerment of parents; (4) separating the child from the illness through externalisation; and (5) an initial focus on ED symptoms. FBT differs from other treatments for adolescent $\mathrm{AN}$ as it mobilises the parents to utilise their authority by taking action to change ED behaviours in order to enable weight restoration. This focus on weight restoration takes precedence over other issues of adolescent functioning (with the exception of suicidality) (c.f. Lock \& Le Grange, 2013).

\section{Structure of treatment}

FBT typically consists of $15-20$ sessions and is divided into three phases over the course of approximately 12 months. The first phase of treatment aims to re-invigorate the parental role. The primary focus of this phase is on AN symptoms, promoting parental alliance, and strengthening their efforts to address the ED behaviours. Prior to the family session, the therapist spends approximately 10 minutes alone with the adolescent for weighing. During this time, the adolescent is encouraged to discuss how he/she feels with the aim of developing the therapeutic alliance. However, unlike directed individual therapy, there is no exploration of issues not closely linked to nutritional restoration. The adolescent's weight sets the tone of the family sessions and the review of the weight chart keeps the family focused on the AN. The therapist directs the discussion to food and eating, integrates psycho-education about $\mathrm{AN}$, and provides information about nutrition. The therapist intervenes to reduce parental feelings of guilt, and also works to block criticism of the adolescent by externalising the disorder.

The second phase begins when parents are more confident in their ability to manage the adolescent's eating and weight gain. Additionally, the patient must have attained approximately $90 \%$ of Expected Body Weight (EBW) and exhibit significantly less eating-related struggles. The aim of this phase is to support the adolescent in managing their own eating behaviours under parental guidance. Further, the family 
is encouraged to address other issues associated with eating (e.g., socialising, participation in sports). Phase three begins when the adolescent has reached approximately $95 \%$ of EBW and is eating independently. The aim of this phase is to ensure the adolescent is on a normal developmental trajectory and the family is able to manage concerns related to building autonomy, navigating parental roles, and related themes without these being mediated by the AN.

\section{Overview of empirical support}

The efficacy of FBT for adolescent AN has been tested in a number of randomised control trials. In the first study, Russell, Szmukler, Dare, and Eisler (1987) demonstrated that FBT was particularly efficacious for adolescents less than 18 years of age with a short duration of illness. Trials have shown FBT to be more effective than individual treatments for adolescent weight restoration (Lock et al., 2010), with more rapid recovery rates (Robin et al., 1999). Furthermore, treatment gains in FBT have been maintained at four-year follow-up (Lock, Couturier, Bryson, \& Agras, 2006). Comparison of conjoint (adolescent and parents) and separated (parents alone) forms of FBT showed equivalent end-of-treatment results; however, separated FBT demonstrated a superior outcome for families with higher levels of maternal expressed emotion (EE) (Eisler et al., 2000). Findings were sustained at five-year follow-up (Eisler, Simic, Russell, \& Dare, 2007).

Research has also shown that less than half of adolescent patients receiving FBT achieve weight restoration at the end of treatment. In a study by Lock et al. (2010), patients were randomised to either FBT or adolescent-focused individual therapy (AFT) $(\mathrm{N}=121$, aged $12-18$ years). The results showed $41.8 \%$ of the FBT group attained full remission at post-treatment compared to $22.6 \%$ of the AFT group. At 12-month follow-up, patients reached a remission rate of $49.3 \%$ (FBT) and $23.2 \%$ (AFT). Finally, at four-year follow up, there were no differences in remission rates between AFT and FBT; rate of remission was $31.6 \%$ for the combined groups (Le Grange et al., 2014).

Thus, whilst FBT is the treatment of choice for adolescent AN, there is a pressing need to: (1) augment the treatment; and/or (2) develop efficacious alternative models to help those who do not attain or maintain full remission.

\section{FBT augmentations}

Eisler et al. (2010) considered that, if systematic progress is not established, it may be necessary to explore the role of $\mathrm{AN}$ in regard to dealing with emotions, feelings, and interpersonal relationships, but with the focus on how these dynamics have developed around the disorder. In this respect, several augmentation strategies have been proposed. The Eisler et al. (2000) study demonstrated separated family therapy was more effective for families with higher Expressed Emotion (EE) and maternal criticism than conjoint family therapy; it also found an association between the need for further treatment and maternal EE at initial assessment for both groups. Thus, whilst these augmentations of FBT are helpful for many, some families continue to experience relational problems that may affect the course of the disorder.

Other parent-focused augmentations to FBT include parent-focused treatment (Hughes, Sawyer, Loeb, \& Le Grange, 2015), for which only parents attend treatment sessions, although the adolescent remains the target of treatment. This model proposes that reducing the adolescent's exposure to counterproductive expressions of parental 
Ingrid Wagner et al.

criticism or minimising the disruption of the session by the adolescent's difficult behaviours may improve treatment effectiveness. Second, Fitzpatrick, Darcy, Le Grange, and Lock (2015) proposed a second family meal session for initial FBT nonresponders. In a supplementary session prior to the second family meal, the parents are coached in emotional coping techniques to regulate their emotions and manage the adolescent's distress to reduce escalations of conflict and EE. Third, Hopf, Hoste, and Pariseau (2015) overview a range of parent group interventions that combine psychoeducation and skill development with support received from other parents, which target caregiving burden. They proposed that such groups may reduce high EE and help parents to modify overly high expectations, which potentially increase critical comments toward the young person.

Two further augmentations of the FBT model address both parent and adolescent distress. Bhatnagar and Wisniewski (2015) proposed integrating dialectical behaviour therapy (DBT) with FBT (FBT-DBT) for adolescents with affect dysregulation. In FBT-DBT, the treatments are delivered in parallel - the adolescent patients attend DBT sessions and their parents attend weekly skills training sessions in addition to the FBT session. Finally, Zucker (2015) draws upon attachment theory to suggest that the deficits from starvation are not only physical but also impact self-awareness, self-trust, and self-knowledge, leading to attachment insecurity. As a consequence, the individual's behavioural repertoire is narrowed and the availability of a range of emotional regulatory strategies is affected. She proposed using the emotion regulatory frameworks of Gross and Thompson (2007) to understand the function of ED symptoms and inform strategies for integration into FBT. She argues that this model will potentially allow parents to continue engaging in FBT rather than misinterpreting the effect of the treatment as failure.

\section{The role of relational dynamics in maintaining adolescent AN}

Although no preferred model has emerged, the augmentations to FBT honour its agnostic approach and attention to parent empowerment. However, as a corollary there has been less focus on the quality of parent-child relationships as a key element in the interpersonal problems that may contribute to the maintenance of FBT. Adolescent disordered eating has been consistently associated with the following, which affect treatment outcomes: (1) family problems such as conflict; (2) parental distress (e.g., depression, anxiety, alcoholism); (3) higher levels of EE, maternal criticism, and low parental warmth toward the patient; (4) parent history of psychiatric illness; and (5) individual patient factors such as older age and co-morbid psychiatric disorders (depression, anxiety, and obsessiveness) (Le Grange, Eisler, Dare, \& Hodes, 1992; Le Grange, Rienecke Hoste, Lock, \& Bryson, 2011; Lock et al., 2006; Polivy \& Herman, 2002; Toker \& Hocaoğlu, 2009).

Ciao et al. (2015) note that although the literature reports families of children with AN show more impairment in family functioning than non-clinical samples, there is no empirical support for a direct relationship between family dysfunction and the development of ED pathology. The results of their study showed aspects of family functioning improved from baseline with FBT; however, these improvements were not related to remission. Hence, it remains uncertain if changes in family dynamics facilitate recovery or reflect improvement in ED symptoms due to treatment. Nevertheless, positive family factors such as family connectedness, perceived maternal and paternal acceptance, and positive family communication have been demonstrated as 
protective factors (Allen et al., 2014; Croll, Neumark-Sztainer, Story, \& Ireland, 2002; Fonseca, Ireland, \& Resnick, 2002).

There is substantial research linking the quality of parent-child attachment to EDs (c.f. O'Kearney, 1996; Ward, Ramsay, \& Treasure, 2000; Daae Zachrisson \& Skarderud, 2010). A review of empirical studies published between 2000-2014 (Tasca \& Balfour, 2014) found over 70\% of adults with EDs reported an insecure attachment to parents, compared to non-clinical controls. Lower reflective functioning was specifically associated with AN. Attachment anxiety was associated with ED symptom severity, and was potentially mediated by perfectionism and affect regulation. Higher attachment avoidance led to treatment dropout, while higher attachment anxiety led to poorer treatment outcomes. The factors that impact relational security (i.e., parental criticism, low parental warmth, familial conflict, and adolescent affect intolerance) are the same factors that affect the outcomes of FBT.

The success of FBT, the need for augmentations to help potentiate FBT outcomes, and the substantial literature linking interpersonal functioning and ED symptoms, indicate the potential significance of an augmentative therapy focused on the quality of parent-child relationships. ABFT (Diamond et al., 2014) may provide a treatment technology that could target these domains and make a significant contribution as an augment to FBT.

\section{Overview of ABFT}

ABFT is an empirically supported treatment that has been successfully tested in several clinical trials and process research studies (Diamond et al., 2014). ABFT posits that when adolescents are able to use their parents as a source of support and resources, their ability to emotionally regulate improves.

\section{Structure of treatment}

ABFT aims to repair ruptures in the attachment relationship between parents and adolescents and establish (or resuscitate) the secure base that can reduce family stress or buffer against stressors outside the home (e.g., bullying, academic pressures). There are five treatment tasks that comprise the model. Task 1 focuses on establishing improvement in family relationships as the first goal of therapy. Task 2, with the adolescent alone, helps the adolescent identify and articulate perceived experiences of the attachment ruptures and prepares him or her to discuss these with their parents. Task 3 , with the parent(s) alone, encourages parents to consider how current stressors and/ or their own intergenerational attachment legacies affect their parenting style. This task motivates parents to want to be different with their children, increasing their receptiveness to emotion-coaching skills. In Task 4, the adolescent and parent(s) discuss, validate, and try to resolve these past attachment ruptures. As the parent(s) acknowledge the adolescents' thoughts, feelings, and memories, their adolescents become more self-reflective, emotionally regulated, and cooperative. Finally, Task 5 focuses on using the parent(s) as a secure base to support adolescents' exploration of competency and autonomy.

\section{Empirical support}

ABFT has proven efficacious for adolescents with depressive disorders, suicidal ideation and behaviours, as well as for those suicidal adolescents with a history of sexual 
Ingrid Wagner et al.

abuse/trauma (Diamond et al., 2012; Diamond et al., 2002; Diamond et al., 2010; Diamond et al., 2014; Israel \& Diamond, 2013). ABFT is listed on the Substance Abuse and Mental Health Service Administration's National Registry of Evidencebased Programs and Practices (NREPP) website and has received high scores for quality of research and dissemination readiness.

\section{Comparison of ABFT with FBT}

ABFT and FBT are both intentional therapies focused on adolescent disorders and are inclusive of the family. Both models view the parents as part of the solution as opposed to the cause of the disorder. ABFT and FBT are well-delineated treatment models that are supported by empirical evidence. They both provide structure, goals, and a map of therapeutic interventions to guide clinicians. Both have been influenced by structural family therapy (Minuchin, 1974); however, FBT, like structural family therapy, focuses on behavioural change, while ABFT focuses on improving the interpersonal and emotional climate of family life. In ABFT, the in vivo experience of enactment helps adolescents restore trust in the security of the parent-child relationship. This encourages parents to practice emotion-focused and attachment-promoting parenting skills.

\section{Treatment focus}

A significant difference between ABFT and FBT is the treatment focus. FBT focuses on food and eating and uses 'externalisation' to coalesce the family in their efforts to defeat AN. In contrast, ABFT focuses on the quality of parent-child attachment relationships, and addresses and repairs long-standing interpersonal ruptures in the attachment relationship. Attachment ruptures serve as the central topic of conversation (e.g., abuse, neglect, abandonment, divorce, domestic violence, parental criticism and control). This brings to the foreground conflicts that usually linger in the psychological background and drive negative family interactions. Preparing and facilitating these kinds of 'attachment repairing' conversations not only helps resolve specific interpersonal process issues, but also improves parent and child emotion regulation skills. This occurs while the family practices new, more positive, interpersonal problem-solving skills.

\section{Parental control and adolescent autonomy}

Another critical difference between FBT and ABFT is the approach to parental authority and adolescent autonomy. In FBT, as with structural family therapy, treatment aims to re-establish parental authority and control. Without effective leadership, the family system devolves into disorganisation and chaos. For adolescent AN cases, establishing parental hierarchy becomes essential for supporting the adolescent to eat sufficient food for nutritional restoration.

The ABFT model views parental hierarchy as important, but not with the purpose of behavioural management. For many adolescents with AN, the disorder has caused such significant stress in the family that the adolescent may no longer see the parent $(s)$ as helpful or trustworthy. In other cases, a history of relational disappointments or traumas may have damaged trust in the relationship. These relational disappointments might include marital conflict, divorce, financial stress, or parental illness (e.g., depression or cancer). These kinds of family challenges may rupture an adolescent's expectation of love, protection, and emotional sensitivity. Whether these ruptures result from the ED 
or pre-date it, adolescents may be resistant to parental authority (e.g., 'You have not been there for me in the past, why should I listen to you now?'). ABFT does not propose that these family conflicts 'cause' the ED or that parents are to blame for the treatment failure. When the foundation of attachment has been ruptured, however, parental authority can feel more like a power struggle than support and protection. Thus, instead of leading with parental authority, ABFT leads with promoting adolescent maturity by helping the adolescent better understand how relational ruptures have affected their selfdestructive behaviour. Adolescents are assisted in accessing and tolerating primary emotions associated with these ruptures (e.g., sadness instead of anger or assertive anger instead of depression), and helped to talk directly to their parents about these issues, rather than avoiding them.

Thus, in ABFT, the initial goal is to identify and bring into conversation these core relational ruptures. If the family can learn to tolerate difficult, but honest and productive discussions, the attachment fabric begins to mend. When it does, adolescents become more motivated to let their parents help them. In this regard, the initial goal of ABFT is not to control the adolescent, but to help them develop a mature, emotionally regulated and appropriately entitled voice, to both stand up for themselves effectively as well as understand others' points of view (e.g., reflective functioning) (Fonagy \& Allison, 2012).

\section{Augmenting FBT with ABFT}

The integration of FBT and ABFT requires flexibility and clinical judgement, but there are several guidelines. First, physical stabilisation is required before one can successfully implement a more 'reflective' or interpersonal therapy (c.f. Cook-Darzens, Doyen, \& Mouren, 2008). In this regard, FBT remains the preferred first line of intervention due to superior weight gain and lower hospitalisation rates associated with the model (Lock \& Le Grange, 2013). Second, unlike other augmentation models (Bhatnagar \& Wisniewski, 2015; Zucker, 2015), the goal is not to 'integrate' ABFT into FBT. ABFT brings a paradigmatic change; the proposed targets of change for ABFT (emotions) are very different than FBT (behaviours). Therapists shift their focus from nutritional restoration to the restoration of trust. Facilitating these goals simultaneously might confuse both the family and the therapist. Further, it could create a rupture in the therapeutic relationship with the adolescent since they do not generally identify issues of food and eating as their primary concerns and ABFT and FBT handle this differently. In ABFT, the focus is relational and adolescent-led; in FBT, the focus is food and eating and parent-led, and to shift between ABFT and FBT could be perceived as dismissing the adolescent's view.

\section{Transition to ABFT}

Instead of integrating the two treatments, ABFT is introduced when the progress of FBT has stalled. Typically, this occurs in Phase 2 of FBT when physical stability has been achieved and other interpersonal problems begin to surface. At this time, some adolescents begin to engage in suicidal or self-harm behaviours. Others are unable to accept their parents' help in transitioning from parental guidance to independence and either stall at a non-optimal weight or lapse into weight loss. Their resistance to parental help may take various forms: angry outbursts and refusal to comply, for instance, or passive resistance to their independent management of food and eating. Finally, of those adolescents who attain remission but relapse after the end of 
Ingrid Wagner et al.

treatment, some are reluctant to re-engage in FBT and may present similarly to those who resist parental help in Phase 2.

Faced with these types of challenges, transition to ABFT may be a helpful secondstage treatment, when all attempts to reinvigorate FBT have failed. Hypothetically, supporting young people to return to health involves supporting them to become more independent, and to do so successfully requires that they use their parent(s) as a secure base and turn to them for help with managing their eating disorder symptoms. If there is an attachment rupture, the young person may avoid or dismiss parental assistance and might have more negative emotions and difficulties with emotional regulation which are the target of ABFT.

As a second-stage treatment, ABFT capitalises on the foundation set by FBT. Although the initial crisis has abated, the adolescent's health still requires monitoring to ensure safety, and the family is asked to continue this routine. Further, the parents have been educated to understand the issues associated with AN, experienced some success in challenging the eating disorder symptoms, and know how to manage their child's nutritional requirements. Therapists continue to weigh the young person throughout therapy and report the weight to parents to reassure them that he/she is aware of the adolescent's state of health.

When shifting from FBT to ABFT, consideration should be given to issues that may have an impact on therapeutic alliance, particularly if the same therapist/s does both treatments. Developing therapeutic alliance is challenging for clinicians working with patients with AN due to the ego syntonic nature of the disorder (Guarda, 2008), and it has been shown to be significantly lower for FBT in comparison to Adolescent Focused Therapy (AFT); however, it does not negatively affect treatment outcomes (Fosberg et al., 2013). In contrast, in ABFT, developing a good alliance with the young person is essential. Therefore, when transitioning from FBT to ABFT, therapists must address any ruptures between the therapist and the patient that might have been incurred during the FBT treatment. For example, adolescents who have had to forfeit places in elite teams or academic activities due to the impact of the eating disorder often resent the therapist for this loss. Addressing these ruptures directly facilitates the transition to ABFT.

\section{Case Study: 'Charlie'}

Charlie was a 17-year-old girl who had completed the 10th grade. She lived with her mother, father, and two younger brothers. She had two older brothers who did not reside in the home. At age six, Charlie underwent cardiac surgery and was hospitalised for several months. She was diagnosed with Attention Deficit Disorder at age eight, Obsessive-Compulsive Disorder at age 12, Depressive Mood Disorder at age 15, and AN at age 16. Charlie went to inpatient treatment twice - once for her depression and suicidal ideation at age 15 and once for her AN at age 16. Upon discharge for the second hospitalisation, Charlie was referred to the Eating Disorder Clinic (EDC) of the Child and Youth Mental Health Services, Lady Cilento Children's Hospital.

The family attended 14 sessions of FBT at the EDC and had transitioned to Phase 2 of treatment. Charlie's weight increased by six kilograms across the course of treatment; however, when Charlie's weight decreased and stalled at $87 \%$ of EBW, ABFT was recommended. As the EDC operates on a co-therapy model, a therapy team conducted ABFT. Both therapists, Ingrid Wagner and Richard Litster, were 
trained in FBT and ABFT, but were not the FBT therapists for this family. The family consented to use of their clinical material in this case study. Names and other identifying information have been changed to protect the identity of the family.

\section{Presenting history}

The parents reported that, at home, Charlie was smashing plates and glasses at the dinner table, and frequently punching holes in the wall. During the FBT sessions, Charlie had angry outbursts directed toward both her parents and the therapists, frequently screaming that she did not have an ED and no one was listening to her. The parents felt exhausted by Charlie's behaviour, were at a loss to understand her pain, and worried that they were unable to help her. Charlie wanted to leave home and live with a friend, Jane, who she thought better understood her and who she believed was 'the only person who helped her feel calm.'

At the start of ABFT, the clinic team discussed strategies for monitoring weight and nutritional status without compromising the shift to a different treatment model. The parents were advised to continue their usual reviews with their general practitioner. The psychiatric review remained at six-week intervals and the ABFT therapists monitored weight prior to each session, similar to FBT. Unlike FBT, however, the weight did not determine the tone of the therapy session.

\section{Task 1: Relational reframe - One session}

In the first ABFT session, the parents were very focused on Charlie's history of problems. They described a progression from a once happy childhood, to school problems, arguments with teachers, withdrawal from school, loss of friends, withdrawal from the family, depressed mood, deliberate self-harm, restricted eating, and the emergence of aggressive and oppositional behaviours. The parents described feeling frightened of their child and concerned for the safety of their other children, a loss of hope for the future, and powerlessness to alter the negative trajectory of Charlie's life. To create a different kind of narrative in the therapy, the therapists shifted focus from behaviours and symptoms to the parent-child relationship. This created an affective movement from feelings of failure and frustration to longing, disappointment, and sadness. This was a challenging transition as Charlie's behaviours were frightening to her parents.

To begin transforming the conversation, the therapists first acknowledged the parent's love for their daughter and validated their efforts, frustration, and loss: 'We can see that you are great parents and clearly you love your child. You have worked very hard to help Charlie return to health. It must be very painful to have come so far with FBT and have progress stall. You must feel so worried and frightened.' Shifting the emotional mood from panic and frustration to disappointment and worry helped the parents calm momentarily. In the past, while overwhelmed with panic and despair, they rarely stopped to acknowledge the pain and loss regarding their daughter.

During this process, Charlie sat on the opposite side of the room, crying by herself. The therapists asked the parents to look at Charlie, and wonder what she might be feeling. Mother replied, 'Sad ... I think she is feeling sad.' Charlie responded, 'I am not sad, I am angry!' The therapists let the silence linger for a few moments. Trying to move Charlie to sadness before validating her anger would have increased her resistance. The lead therapist then asked Charlie to talk about the time she felt most angry. Charlie described an argument with her parents about her friends and how 
Ingrid Wagner et al.

dismissive the parents were of her relationships. Charlie described becoming enraged and smashing her fist into the wall. The therapists noticed Charlie was trembling and tearful, and the lead therapist said, 'I wonder if, in that moment Charlie, you felt frightened and all alone; like no one understood you.' By speaking to Charlie's feelings of despair, the therapist allowed the emotion in the room to soften. Charlie began to sob and, spontaneously, her mother moved over to hug and comfort her. Charlie turned to her mother and allowed herself to be held. They had not shared this kind of tenderness in a long time.

Avoiding the conflict-laden topic of food and eating, the therapists helped the family experience a moment of attachment security: the daughter was hurting and the mother was attentive and supportive. For a moment, this mother and daughter experienced a warmth that had been buried by years of mental health struggles. While mother held her daughter, the therapist continued to explore the ruptures in their relationships.

Therapist 1: (to the parents) When Charlie is in so much pain and distress she needs someone to help her calm down. What stops her from coming to you for help?

Mother: We want to help her but she doesn't let us.

Adolescent: I stopped going to them because they don't listen to me ... I don't have an eating disorder and last time I said how I felt, I got put into hospital ... I just don't trust them. I don't trust anyone except Jane.

Therapist 2: (turning to Charlie) How has not being able to go to your mum affected you?

Adolescent: I just have all this anger inside me.

Therapist 1: I see how angry you are ... but I also see how lonely you are ... Is that right?

Adolescent: (nods in agreement; starts to cry again)

Therapist 1: There is a lot going on for this family. A lot of things have caused both anger and pain, but what worries me most is that Charlie will not turn to you for help. Something is getting in the way of love and safety in this family. I worry that this illness has created distance between everyone. And that everyone feels alone. Is that possible? (family members agree) So ... if I could help you find a way to get back together ... to feel more connected ... to feel like a family again, would that be a good initial goal for our work together? Would you be willing to work on making your relationship better? (parents strongly agree ... Adolescent shrugs)

Shifting the focus from AN to the relationship allowed Charlie to express her feelings of anger, loneliness, and distrust. Charlie's parents expressed their desire to try something new. Charlie, however, expressed her distrust of therapy and the therapists, and remained non-committal. The therapists accepted her ambivalence and just asked that she come back to the next session, to which she agreed. With this relational reframing, the focus of therapy shifted from controlling the ED to repairing the ruptured relationship. 


\section{Task 2 - Adolescent alliance}

The therapists met with Charlie alone, with the ultimate goal of preparing her to talk with her parents in Task 4. The therapists had four Task 2 sessions with Charlie and began the first meeting by shifting the focus from FBT to ABFT: 'We know a lot about the anorexia but we don't know a lot about you. Today we want to get to know you better. Would that be okay?' Charlie said that she did not have an ED so she was relieved to talk about other parts of her life. Charlie began talking about her family and her concern that she was 'too much' for her parents to manage. Charlie vacillated between accusing her parents of being overly critical and controlling and feeling shame and guilt for being so much trouble. She felt that her brothers had always been treated better because she was 'always the problem.' She saw no link between this predicament at home and her eating behaviour and depression. In fact, she had a very disorganised story about these challenges, shifting from anger to selfblame, with no coherent understanding of what she was feeling and how it affected her.

In the following session, the therapists began to help Charlie build a more coherent attachment rupture narrative. The therapists started with genograms and eco-maps to help her to describe people, places, events, and relationships that were meaningful in her life. Putting these stories into a temporal sequence, Charlie, for the first time, began to see some patterns and themes. Starting with her surgery at age six, she recognised how a series of school challenges was initiated, leading to social failures and family conflicts. She described her parents as overprotective, yet unresponsive at times when she needed help. As she became more depressed, her parents seemed increasingly impatient and emotionally unavailable. When the AN began, her parents appeared even more controlling and angry, and even less emotionally available. As this storyline became clearer, she acknowledged her deep emotional despair: feeling ostracised, lonely, misunderstood, abandoned and, ultimately, unlovable. Although not an easy conversation, understanding these emotional experiences left Charlie feeling calmer and more curious about herself. The next few sessions explored similar material, helping her consolidate a new understanding of the painful experiences in her life, how unfairly she had been treated, and how these events had left her hurt and distrustful of others.

In the third Task 2 session, the therapists introduced the idea of Charlie sharing some of these revelations with her parents: 'I wonder if your parents have any idea that you feel this way. Or do they only see anorexia?' After some discussion of this, the therapist asked, 'Have you ever talked to them in the past about these feelings?' Charlie said that these conversations quickly turned into arguments: 'They think that they listen but they don't and they don't really care. And besides, they never listen to me. They always think there is something wrong with me. It always comes back to the eating disorder. Whenever I get mad about anything, it is the eating disorder!' The therapists empathised with Charlie's distrust of her parents, but also encouraged her to consider discussing her feelings with them by reminding her how lonely she felt. The therapists also reminded Charlie that she had previously said a part of her wished her mother understood her better. Finally, Charlie was challenged to think about how her parents would never take her seriously if she communicated by becoming enraged. Charlie agreed with the therapists, but also said she just gets so angry when they do not let her go out. The lead therapist followed up by challenging this 
Ingrid Wagner et al.

as well: 'The argument with your parents is not about rules, chores, and going out. It is about trust, respect, abandonment, and loneliness. If you would share your thoughts and feelings about these disappointments, your parents might listen in a new way. The anorexia has become a wall between you and you want them back; to love you in spite of this.'

Charlie was a bit confused. She agreed with the therapist but also worried that talking about her feelings would burden her parents and make them feel bad: 'It is better if I just talk to Jane, and don't expect anything from them.' The therapists pointed out that Charlie's protection of her parents' feelings was yet another example of her love for them, but, in fact, her parents missed her: 'They are here for you. They have been here for you. When they make you eat, it is not to punish you. It is because they love you and are worried that you might die. But they have no idea what you have been through. If you really care about them, tell them how you feel ...'

As Charlie developed a more coherent story about her struggles, one that helped her understand and justify her feelings, she became less defensive about discussing her AN. She was better able to reflect on what the story meant and how it affected her life. She began to see her parents' control as an attempt to help even though it hurt her feelings and made her angry. With these shifts in thoughts and feelings, the therapists, again, introduced the possibility of Charlie talking directly to her parents about her attachment ruptures: 'You know, I have been working with your parents, teaching them how to listen to you in a new way ... What if they could really hear the new things you are thinking and feeling? Would you be willing to try?'

Charlie remained hesitant. She was not sure she could control her anger, and felt scared that they might give up on her. The therapists empathised with her fear but validated her right to be heard: 'You deserve to have your side of the story told.' The therapists also helped Charlie think about what she would say to her parents if she decided to participate in Task 4. The therapists assured Charlie that they would be there to coach and support her during this conversation. With the focus off the AN, Charlie finally agreed to talk with the parents about her attachment ruptures. She was also willing to discuss how she felt distrustful and resistant when her parents tried to help with the AN.

\section{Task 3 - Parent alliance}

The therapists met with the parents together three times during Task 3. In ABFT, meeting with the parents individually allows them to prepare for the attachment task (Task 4). To help manage their anxiety about the AN, the therapists started the session by allocating 10 minutes to discuss the eating management. Fortunately, the sessions alone with Charlie coincided with some weight gain $(1.2 \mathrm{kgs})$ and fewer emotional outbursts. Thus, the parents were hopeful about the new direction of the therapy.

The first parent session began with a focus on current stressors. The only stress the parents experienced was from attempting to manage Charlie's behaviour and its impact on the family. Sympathising with the parents' challenges and fears, the therapists asked the mother to share her view of Charlie's struggles. The mother described how Charlie's history of medical and mental health issues impacted her school and social life. She admitted that, at times, she was overprotective, fearing that Charlie was too vulnerable. In fact, mother revealed that her restriction on Charlie seeing Jane 
was not about food, but about her worry that Jane would take advantage of her daughter. The father also admitted that he was impatient with Charlie and rarely gave her the chance to demonstrate her strength. This conversation uncovered some parenting conflicts between mother and father about their different approaches to managing Charlie's behaviour. Mother was angry at the father for being impatient and father felt a bit marginalised by the mother when she would take over. After some discussion, the therapists brought the focus back to Charlie: 'You both clearly care about her, but sometimes the way you try to help makes Charlie feel overprotected and lonely. Maybe it is time to re-think some of your differences and your strategies.'

In the next session, the therapists explored the parents' experiences growing up in their own families and their relationships with their parents. Both parents described growing up in large families in rural Australia. Although they both felt close to their parents, talking about feelings was not common. They viewed their small rural communities as stoic, and people's experiences of loss and hardship as '... that's just how it is and you just get on with it.' They admitted this made it hard to understand Charlie's feelings. The therapists suggested that Charlie needed a different kind of parenting approach than the parents received in their families of origin, as she was an emotional young person with a lifetime of challenges and difficulties. The parents came to understand this and expressed a willingness to learn some new parenting skills and to give Charlie more opportunities to talk about her own suffering. This led to a final Task 3 session, focused on teaching the parents emotion-coaching skills that would facilitate emotional expression.

\section{Task 4 - Attachment task}

The family attended four Task 4 sessions. The therapists supported Charlie to discuss her attachment ruptures and her parents to provide emotional support for Charlie. The therapists opened the session by orientating Charlie and her parents to the task. Charlie hesitantly started speaking.

Adolescent: You don't treat me the same as my brothers.

Mother: (restraining her self-defence) Can you say some more about that?

Adolescent: You give me more chores to do than them and you don't notice when I've done them. I can never do enough to make you happy.

Mother: That is not true. I ...

Therapist 1: Mum let's just slow down here. Maybe ask Charlie if she has more she wants to say.

Adolescent: And you don't let me go out with my friends. You always say that you will think about it but then just say no anyway. It's not fair and I am sick of it. I want to have a life.

Mother: (at a loss about what to say)

Therapist 2: (although there is lots of good content here, the therapist encouraged the mother to focus on Charlie's feelings) Mum, ask her more about how it feels.

Mother: Well can you tell me about how you feel?

Adolescent: I don't know it's just like hard ... 
Ingrid Wagner et al.

Mother: What is hard?

Adolescent: Just fighting all the time with you.

Mother: Do you mean like when you and I argue about food?

Adolescent: (nods, yes)

Mother: I know that is hard for you.

Adolescent: (mother's validation helped encourage Charlie's expression) Like sometimes I just get so angry. That is when I go to my room 'cause I feel I can't stop it. (Charlie's anger begins to soften) And I worry you will get angry with me and ... like I am just too much trouble (becomes tearful) and you ... You will just give up on me'. (begins sobbing)

Mother moved to comfort Charlie, and Charlie accepted her mother's embrace. While holding her, the mother reassured Charlie that she was not angry with her and not feeling burdened by her. But rather than move the conversation to reassurance, the therapists encouraged the mother to stay close but ask more.

Adolescent: I'm lonely and I'm sick of being at home all the time. Everyone else gets to go out. I'll just be left out and then won't have any friends. It's not fair I've been eating okay and I haven't lost weight and when you don't let me go out it just makes me feel like you don't trust me and I just want to give up. (Voice rising to a yell)

Therapist 1: Charlie, slow down, you're doing great. Make sure they hear you. (Charlie was able to regulate herself)

Mother: When you say you just want to give up, what does that mean to you?

Adolescent: (crying) There's nothing ... nobody to be with ... I don't have a job or anything that I can do ... I want to do something ... be with Jane and everyone ... you won't let me go and stay over for the party ... they are just going to go on and forget me .... (mother comforted Charlie and both parents shared their perspectives about their concerns about managing eating while Charlie spends time with her friends).

Father: We don't want to stop you from having friends and doing things but we worry about you staying well. We nearly lost you and that was a frightening time for Mum and me.

Mother: We don't want you to go through that again ... being in hospital that was hard ... I know you've been good with eating but this was a bit longer (overnight) and ... maybe I just don't trust that Jane's family will have things that you can eat ...

Adolescent: I know that they don't eat breakfast and that they all sleep in late and don't get up 'til after 10. I don't want to stay there and not eat properly that's why I eat before I go and I call you in the morning so I can come home so I don't miss eating breakfast. I know it's important.

Mother: (the mother was very surprised to hear that Charlie had thought about this. It helped the mother see a new side of Charlie, a more mature and reflective daughter) Okay, you're right. You do that and you do come home to eat. Maybe I should trust 
you more. I just worry that you will get sick again and I don't want to see that happen.

Adolescent: Mum you have to let me go out. Sometimes I still need help with eating and that, but you have to let me be with my friends and go out and do things with them.

Mother: You're right. You're right. You have been responsible with your eating, and you are growing up and I didn't really take it in and ... well I am so sorry ... And so proud of you.

This was the first time the mother listened and validated Charlie's point of view. It was also the first time Charlie was willing to understand her parents. The more the mother listened, the more Charlie felt free to express herself and understand her mother's perspectives. This, and future Task 4 conversations, began to shift the relational dynamics from control and submission to a more age-appropriate, goal corrected partnership ([GCP]; Bowlby, 1969). Both parents and Charlie were invested in maintaining the relationship, thus promoting compromise around problem solving. Making progress on these developmental issues helped build enough good will so that the AN management could be discussed collaboratively. The parents reported that Charlie had started asking for help in monitoring her food intake.

The family went on to address other ruptures in the remaining Task 4 sessions. Charlie was able to discuss how she sometimes felt emotionally abandoned by her father; that she reached out but he did not respond. Her father was receptive to this feedback, acknowledged his role in this, and promised to do better. Charlie also talked about her school problems in elementary years and the mother's tendency to ignore them as a passing phase. Mother apologised for failing to recognise Charlie's distress, and later, shared her guilt for not supporting her.

As the attachment task progressed, Charlie's mood lifted and both she and her parents reported fewer arguments home. As the parents became more aware of how they could reduce differential treatment among the siblings, Charlie began to join family activities with her brothers. Charlie was able to turn to her parents more as she experienced them in a more caring and supporting way. In one session she stated, 'When I feel irritated and angry sometimes I go talk to mum about stuff and it calms me.' The parents reported that Charlie was managing her emotions and was more able to consider her parents' points of view. These changes allowed Charlie to better balance allowing her parents to help with the eating along with promoting her feelings of independence. Charlie was able to begin developing a life outside the home.

\section{Task 5 - Autonomy promoting}

In Task 5, the family supported Charlie in developing autonomy and competency, while in Task 4, the family was primarily focused on discussing interpersonal problems between Charlie and her parents. In these next sessions, the family discussed many of the topics specific to Task 5: building maturity in the home, developing competency outside of the home, addressing factors that contribute to the adolescent's eating disorder, and discussing identity development. The family spent four sessions in Task 5. They specifically addressed spending more time with Jane and preparing for a career by enrolling in a vocational education program. 
Ingrid Wagner et al.

The most important conversations of Task 5, however, focused on helping Charlie manage her AN. Although Charlie had stabilised her weight at 105\% of EBW, she still had ED thoughts and difficulties eating socially. Charlie found this made it hard for her to participate in social activities where food was involved. With the parents promoting and permitting autonomy, the AN was increasingly becoming Charlie's problem that she wanted to solve, rather than her parent's problem. As the parents avoided the power struggles with Charlie, she increasingly turned to her parents for support and guidance.

As an example of building autonomy Charlie decided to return to school and finish her senior education. In this session, she expressed to her parents her fears about being too far behind, not fitting in with the other students and not being liked by teachers. Rather than dismissing these concerns as ungrounded, or rushing to fix the problem for Charlie, the parents empathised with these fears and offered to help her think about some solutions. Although this 'hands-off approach raised Charlie's anxiety, the parents' support and availability helped Charlie begin to problem solve. With the support of her parents, Charlie decided on the school she would attend, the subjects she would take, how to travel to the school, and most importantly, how she would manage eating during the school day. The subjects Charlie selected required her to be at school during the lunch period and Charlie talked with her parents about her discomfort eating with large groups of people. She worried that eating at school might trigger food avoidance and loss of weight.

Mother: How do you feel about having lunch at school?

Adolescent: I think it will be hard ... I'm still really worried when I eat and having other people around is going to make me worry more.

Mother: Is it just eating or are you worried about something else?

Adolescent: Well, if I start to lose weight maybe you won't let me go to school.

Mother: Anything else?

Adolescent: No.

Mother: Well, your dad and I are committed to helping you return to school and be successful. The last thing we want is for you to quit. Maybe we can help you come up with a solution. What is the lunch situation?

Adolescent: Like there is a big room and everyone sits down together 'cause it is like a shared lunch day. People take turns cooking for everyone and they all sit down to eat.

Mother: Do you have to sit down and eat at the shared lunch?

Adolescent: No but it might be ... I don't know ... funny ... if I was there and didn't.

Mother: So what is another option?

Charlie: Well, there's shops I can go and get food ... like there's a Sushi place that's good. 
Mother: Well, what if we give you some pocket money for a few weeks so you can go out to eat. Then you will have some time to feel out if you could eat in the lunch room. And if not, then sushi for the year!

Adolescent: (smiles) Okay.

Because Charlie felt understood and listened to by her mother, she sought her mother's help managing difficult food situations. In the past, these conversations would have triggered anger and rebellion and were not helpful or supportive. Throughout the ABFT treatment Charlie continued to gain weight and reached $105 \%$ of EBW during Task 4, stabilising between $102 \%$ and $105 \%$ of EBW during Task 5. At the end of the therapy, Charlie had successfully completed a term at school and was planning to increase her subject load in the next term. She had a new group of friends with whom she explored the local area and travelled independently to school on public transport. She still had some AN thoughts, but turned to her mother for help in resisting these urges. Charlie and her parents reported that her angry outbursts had ceased, she was spending more time with the family, and she was more independent in managing her eating. Charlie continued seeing her psychiatrist until she turned 18 years of age. At her final appointment four months post-therapy, she maintained her weight at $103 \%$ of EBW, had no suicidal thoughts or self-harming behaviours, and was still engaged with school. She remained friends with Jane, but had extended her peer group.

\section{Conclusion}

AN is a complex disorder and relapse is a common occurrence in the course of the illness. Both the FBT and ABFT models imply that AN is not only an insidious disease for the adolescent, but also one that impacts the entire family. However, even after FBT recovery, the scars that AN can leave on families might continue to be concerning and, possibly, lead to future relapse. The case study provided an example of how the family struggled to manage these residual scars after Phase 1 of FBT. In this case, ABFT was used when the family was not responding well to FBT in Phase 2. While FBT helped Charlie's parents understand the ED and develop the skills and confidence to help their daughter achieve nutritional restoration, the attachment ruptures prevented Charlie from accepting her parents' help. Charlie's angry outbursts eroded the parents' confidence and capacity to support their daughter in her eating. In this case, $\mathrm{ABFT}$ was not used to treat the $\mathrm{ED}$, per se, but it served to enable Charlie and her parents to effectively work together to manage the symptoms of her disorder. Specifically, this process helped Charlie to become more emotionally regulated and the relational repair work served to re-establish trust in the parent-child relationship. ABFT served to enable Charlie to use her parents as a secure base to obtain support and comfort while managing her ED and building autonomy.

In this paper we have focused on demonstrating the use of ABFT as an adjunct to FBT at Phase 2 of this treatment when progress has stalled, or for young people who relapse post-treatment and do not re-engage with FBT. We also believe that ABFT could offer a useful map for adolescents and their families who have successfully managed Phase 2 of FBT. Phase 3 of FBT has the central theme of establishing a healthy adolescent-parent relationship that is not mediated by AN. Phase 3 of FBT is comprised of three to four sessions at four- to six-week intervals, with the aim of working 
Ingrid Wagner et al.

toward the adolescent's increased personal autonomy, establishing appropriate intergenerational family boundaries, and recognising the need for parents to reorganise their life as a couple (Lock \& Le Grange, 2013).

Many adolescents recovering from AN, however, have difficulties in negotiating the return to normal adolescent life. The sequela of these medical and psychological complications of AN can result in disruptions in family and peer relationships, restricted exposure to social experiences, and potential disruption of future career options. Lock and Le Grange (2013) noted that some adolescents whose treatment has not proceeded smoothly throughout Phases 1 or 2, may harbour anger about their treatment during the weight restoration phase and parents may need to acknowledge their child's anger. In these circumstances, and for families with additional complications, they suggest a separate course of adolescent family psychotherapy may be required. We agree. Even after the recovery that FBT can provide, either long-standing family problems might emerge or the scars that AN has left on the family might continue to impact the family. ABFT may be a useful adjunct at the end of FBT to repair such attachment ruptures and support the parents' and adolescent's continuing return to a normal life trajectory.

\section{Acknowledgments}

The authors thank the Office of Health and Medical Research, Queensland Health, the Child and Youth Mental Health Services, Lady Cilento Children's Hospital (LCCH), and the Queensland University of Technology for the Clinical Academic Fellowship grant that supports this work, and the Eating Disorders Team of the Child and Youth Mental Health Services, LLCH, for their clinical support. Portions of this study have been presented at the Australian and New Zealand Academy of Eating Disorders 13th Annual Conference, Gold Coast, Queensland, Australia, on 22 August 2015.

\section{References}

Allen, K.L., Gibson, L.Y., McLean, N.J., Davis, E.A., \& Byrne, S.M. (2014). Maternal and family factors and child eating pathology: Risk and protective relationships. Journal of Eating Disorders, 2(11).

Bhatnagar, K., \& Wisniewski, L. (2015). Integrating dialectical behavior therapy with family therapy for adolescents with affect dysregulation. In K.L. Loeb, D. Le Grange, J. Lock, K. L. Loeb, D. Le Grange \& J. Lock (Eds.), Family Therapy for Adolescent Eating and Weight Disorders: New Applications (pp. 305-327). New York, NY: Routledge/Taylor \& Francis Group.

Bowlby, J. (1969). Attachment and Loss. New York: Basic Books.

Ciao, A., Accurso, E., Fitzsimmons-Craft, M., Lock, J., \& Le Grange, D. (2015). Family functioning in two treatments for adolescent anorexia nervosa. International Journal of Eating Disorders, 48(1), 81-90.

Cook-Darzens, S., Doyen, C., \& Mouren, M. (2008). Family therapy in the treatment of adolescent anorexia nervosa: Current research evidence and its therapeutic implications. Eating and Weight Disorders, 13(4), 157-170.

Croll, J., Neumark-Sztainer, D., Story, M., \& Ireland, M. (2002). Prevalence and risk and protective factors related to disordered eating behaviors among adolescents: Relationship to gender and ethnicity. Journal of Adolescent Health, 31(2), 166-175. 
Daae Zachrisson, H., \& Skarderud, F. (2010). Feelings of insecurity: Review of attachment and eating disorders. European Eating Disorders Review, 18(2), 97-106.

Diamond, G.S., Reis, B.F., Diamond, G.M., Siqueland, L., \& Isaacs, L. (2002). AttachmentBased Family Therapy for depressed adolescents: A treatment development study. Journal of the American Academy of Child and Adolescent Psychiatry, 41(10), 1190-1196.

Diamond, G.S., Wintersteen, M.B., Brown, G.K., Diamond, G.M., Gallop, R., Shelef, K., \& Levy, S. (2010). Attachment-Based Family Therapy for adolescents with suicidal ideation: A randomized controlled trial. Journal of the American Academy of Child and Adolescent Psychiatry, 49(2), 122-131.

Diamond, G., Creed, T., Gillham, J., Gallop, R., \& Hamilton, J.L. (2012). Sexual trauma history does not moderate treatment outcome in Attachment-Based Family Therapy (ABFT) for adolescents with suicide ideation. Journal of Family Psychology, 26(4), 595-605.

Diamond, G.S., Diamond, G.M., \& Levy, S.A. (2014). Attachment-Based Family Therapy for Depressed Adolescents. Washington, DC: American Psychological Association.

Eisler, I., Dare, C., Hodes, M., Russell, G., Dodge, E., \& Le Grange, D. (2000). Family therapy for adolescent anorexia nervosa: The results of a controlled comparison of two family interventions. Journal of Child Psychology and Psychiatry, 41(6), 727-736.

Eisler, I., Simic, M., Russell, G., \& Dare, D. (2007). A randomised controlled treatment trial of two forms of family therapy in adolescent anorexia nervosa: A five-year follow-up. Journal of Child Psychology and Psychiatry, 48(6), 552-560.

Eisler, I., Lock, J., \& Le Grange, D. (2010). Family-based treatments for adolescents with anorexia nervosa: Single-family and multifamily approaches, in C.M. Grilo, J.E. Mitchell, C.M. Grilo \& J.E. Mitchell (Eds.), The Treatment of Eating Disorders: A Clinical Handbook (pp. 150-174). New York, NY: Guilford Press.

Fitzpatrick, K.K., Darcy, A.M., Le Grange, D., \& Lock, J. (2015). In vivo family meal training for initial nonresponders. In K.L. Loeb, D. Le Grange, J. Lock, K.L. Loeb, D. Le Grange \& J. Lock (Eds.), Family Therapy for Adolescent Eating and Weight Disorders: New Applications (pp. 45-58). New York, NY: Routledge/Taylor \& Francis Group.

Fonagy, P., \& Allison, E. (2012). What is mentalization? The concept and its foundations in developmental research. In N. Midgley, I. Vrouva, N. Midgley \& I. Vrouva (Eds.), Minding the Child: Mentalization-Based Interventions with Children, Young People and Their Families (pp. 11-34). New York, NY: Routledge/Taylor \& Francis Group.

Fonseca, H., Ireland, M., \& Resnick, M.D. (2002). Familial correlates of extreme weight control behaviors among adolescents. International Journal of Eating Disorders, 32(4), 441-448.

Fosberg, S., LoTempio, E., Bryson, S., Fitzpatrick, K., Le Grange, D., \& Lock, J. (2013). Therapeutic alliance in two treatments for adolescent anorexia nervosa. International Journal of Eating Disorders, 46(1), 34-38.

Gross, J.J., \& Thompson, R.A. (2007). Emotion regulation: Conceptual foundations, in J.J. Gross \& J.J. Gross (Eds.), Handbook of Emotion Regulation (pp. 3-24). New York, NY: Guilford Press.

Guarda, A. (2008). Treatment of anorexia nervosa: Insights and obstacles. Physiology and Behaviour, 94(1), 113-120.

Holliday, J., Tchanturia, K., Landau, S., Collier, D., \& Treasure, J. (2005). Is impaired setshifting an endophenotype of anorexia nervosa? American Journal of Psychiatry, 162(12), 2269-2275.

Hopf, R.B., Hoste, R.R., \& Pariseau, C. (2015). Parent support as an adjunct to family therapy. In K.L. Loeb, D. Le Grange, J. Lock, K.L. Loeb, D. Le Grange \& J. Lock (Eds.), Family Therapy for Adolescent Eating and Weight Disorders: New Applications (pp. 139-154). New York, NY: Routledge/Taylor \& Francis Group. 
Ingrid Wagner et al.

Hughes, E.K., Sawyer, S.M., Loeb, K.L., \& Le Grange, D. (2015). Who's in the room? A parent-focused family therapy for adolescent anorexia nervosa. Eating Disorders: The Journal of Treatment and Prevention, 23(4), 291-301.

Israel, P., \& Diamond, G.S. (2013). Feasibility of Attachment Based Family Therapy for depressed clinic-referred Norwegian adolescents. Clinical Child Psychology and Psychiatry, 18(3), 334-350.

Katzman, D. (2005). Medical complications in adolescents with anorexia nervosa: A review of the literature. International Journal of Eating Disorders, 37(S1), S52-S59.

Le Grange, D., Eisler, I., Dare, C., \& Hodes, M. (1992). Family criticism and self-starvation: A study of expressed emotion. Journal of Family Therapy, 14(2), 177-192.

Le Grange, D., Rienecke Hoste, R., Lock, J., \& Bryson, S. (2011). Parental expressed emotion of adolescents with anorexia nervosa: Outcome in family-based treatment. International Journal of Eating Disorders, 444(8), 731-734.

Le Grange, D., Lock, J., Accurso, E., Agras, W., Darcy, A., Forsberg, S., \& Bryson, S. (2014). Relapse from remission at two-to four-year follow-up in two treatments for adolescent anorexia nervosa. Journal of the American Academy of Child and Adolescent Psychiatry, 53 (11), 1162-1167.

Lock, J., \& Le Grange, D. (2013). Treatment Manual for Anorexia Nervosa: A Family-Based Approach. Second Edition. New York: The Guilford Press.

Lock, J., Couturier, J., Bryson, S., \& Agras, S. (2006). Predictors of dropout and remission in family therapy for adolescent anorexia nervosa in a randomized clinical trial. International Journal of Eating Disorders, 39(8), 639-647.

Lock, J., Le Grange, D., Agras, W.S., Moye, A., Bryson, S.W., \& Jo, B. (2010). Randomized clinical trial comparing family-based treatment with adolescent-focused individual therapy for adolescents with anorexia nervosa. Archives of General Psychiatry, 67(10), $1025-1032$.

Loeb, K., \& Le Grange, D. (2009). Family-based treatment for adolescent eating disorders: Current Status, new applications and future directions. International Journal of Child and Adolescent Health, 2(2), 243-254.

Minuchin, S. (1974). Families and Family Therapy. Cambridge, Mass: Harvard University Press.

National Collaborating Centre for Mental Health (2004). Eating Disorders. Core Interventions in the Treatment and Management of Anorexia Nervosa, Bulimia Nervosa and Related Eating Disorders. National Clinical Practice Guideline Number CG9: The British Psychological Society and Gaskell, Great Britain.

O’Brien, K., \& Vincent, N. (2003). Psychiatric comorbidity in anorexia and bulimia nervosa: Nature, prevalence, and causal relationships. Clinical Psychology Review, 23(1), 57-74.

O'Kearney, R. (1996). Attachment disruption in anorexia nervosa and bulimia nervosa: A review of theory and empirical research. International Journal of Eating Disorders, 20(2), $115-127$.

Polivy, J., \& Herman, C.P. (2002). Causes of eating disorders. Annual Review of Psychology, 53(1), 187-213.

Robin, A.L., Siegel, P.T., Moye, A.W., Gilroy, M., Dennis, A.B., \& Sikand, A. (1999). A controlled comparison of family versus individual therapy for adolescents with anorexia nervosa. Journal of the American Academy of Child and Adolescent Psychiatry, 38(12), 1482-1489.

Russell, G., Szmukler, G., Dare, C., \& Eisler, I. (1987). An evaluation of family therapy in anorexia nervosa and bulimia nervosa. Archives of General Psychiatry, 44(12), 1047-1056. 
Strober, M., Freeman, R., Lampert, C., Diamond, J., \& Kaye, W. (2000). Controlled family study of anorexia nervosa and bulimia nervosa: Evidence of shared liability and transmission of partial syndromes. American Journal of Psychiatry, 157(3), 393-401.

Swanson, S.A., Crow, S., Le Grange, D., Swendsen, J., \& Merikangas, K. (2011). Prevalence and correlates of eating disorders in adolescents. Results from the national comorbidity survey replication adolescent supplement. Archives of General Psychiatry, 68(7), 714-723.

Tasca, G.A., \& Balfour, L. (2014). Attachment and eating disorders: A review of current research. International Journal of Eating Disorders, 47(7), 710-717.

Toker, D.E., \& Hocaoğlu, Ç. (2009). Eating disorders and family structure: A Review. Dü̧̧ünen Adam: The Journal of Psychiatry and Neurological Sciences, 22(1), 36-42.

Ward, A., Ramsay, R., \& Treasure, J. (2000). Attachment research in eating disorders. British Journal of Medical Psychology, 73(1), 35-51.

Zucker, N. (2015). Emotional experience and regulation in eating disorders: Theory, evidence, and translational application to family treatment. In K.L. Loeb, D. Le Grange, J. Lock, K. L. Loeb, D. Le Grange \& J. Lock (Eds.), Family Therapy for Adolescent Eating and Weight Disorders: New Applications (pp. 328-358). New York, NY: Routledge/Taylor \& Francis Group. 